\title{
Analisis Perbandingan Pegawai Tetap dan Pegawai Outsourcing Ditinjau dari Pemberdayaan, Kepuasan Kerja, dan Komitmen Organisasional
}

\author{
Ni Made Bella Sintya Devi, Bustanul Arifin Noer, dan Yani Rahmawati \\ Departemen Manajemen Bisnis, Fakultas Bisnis dan Manajemen Teknologi, Institut Teknologi Sepuluh Nopember \\ (ITS) \\ e-mail: bellasintyadevi@gmail.com
}

\begin{abstract}
Abstrak-Dalam meningkatkan kinerja SDM, manajemen dalam perusahaan harus memberikan perhatian yang lebih terhadap para pegawainya. Perusahaan sebaiknya fokus menangani pegawai tetap dan pegawai outsourcing yang ada dalam perusahaan. Karena itu perlu adanya keseimbangan antara pegawai tetap dan pegawai outsourcing yang ada di perusahaan terutama dalam hal pemberdayaan, kepuasan kerja, dan komitmen organisasional pegawai yang terlihat dari aktivitasaktivitas dalam melaksanakan tugas dan tanggungjawabnya. PT. Angkasa Pura I (Persero) Bandar Udara Internasional Juanda Surabaya merupakan salah satu perusahaan di Indonesia yang memberdayakan pegawai tetap dan pegawai outsourcing. Melalui penyebaran kuesioner offline kepada 126 pegawai tetap dan outsourcing, penelitian ini bertujuan untuk menganalisis perbandingan pegawai tetap dan pegawai outsourcing ditinjau dari pemberdayaan, kepuasan kerja dan komitmen organisasional pada PT. Angkasa Pura I (Persero) Bandar Udara Internasional Juanda Surabaya. Analisis data yang digunakan adalah Confirmatory Factor Analysis dan Uji-t. Hasil dari penelitian ini menunjukkan bahwa pegawai tetap memiliki nilai pemberdayaan, kepuasan kerja dan komitmen organisasional yang lebih tinggi dibandingkan dengan pegawai outsourcing.
\end{abstract}

Kata Kunci-Pemberdayaan, Kepuasan kerja, Komitmen Organisasional, Outsourcing.

\section{PENDAHULUAN}

$\mathrm{D}$ ALAM menjalankan bisnis sebuah perusahaan perlu menemukan cara yang kuat untuk mengahadapi perkembangan ekonomi global dan kemajuan teknologi yang cepat guna mempertahankan kelangsungan hidupnya. Keberhasilan perusahaan sangat tergantung pada banyak faktor diantaranya adalah produktivitas, efisiensi biaya, dan manajemen strategis perusahaan yang baik [1]. Persaingan ketat dalam dunia bisnis saat ini membuat perusahaan harus berkonsentrasi pada proses atau aktivitas penciptaan produk dan jasa terkait dengan kompetensi utamanya. Banyak perusahaan yang berhasil menghasilkan sejumlah produk dan jasa dengan kualitas baik dan mampu bersaing di pasaran namun masih kesulitan dalam melakukan efisiensi sehingga biaya produksi yang di keluarkan tetap tinggi. Untuk mengurangi risiko pembengkakan biaya tersebut, banyak pebisnis menggunakan pegawai outsourcing [2]. Dimana pegawai outsourcing memungkinkan organisasi untuk melakukan peran lebih proaktif dan strategis berfokus pada kompetensi utama mereka dalam meningkatkan efisiensi [3].
Untuk mencapai kinerja sumber daya manusia yang lebih baik, manajemen dalam perusahaan harus memberikan perhatian yang lebih terhadap para pegawainya. Perusahaan tidak bisa hanya fokus pada tenaga kerja outsourcing guna meningkatkan efektifitas perusahaan. Namun perusahaan harus memperhatikan pegawai tetap yang juga memiliki peranan penting dalam kemajuan perusahaan. Maka dari itu diperlukan adanya keseimbangan antara pegawai tetap dan pegawai outsourcing yang ada di perusahaan terutama dalam hal pemberdayaan, kepuasan kerja, dan komitmen organisasional pegawai yang terlihat dari aktivitas-aktivitas dalam melaksanakan tugas dan tanggungjawabnya [4].

Pemberdayaan dapat mempengaruhi pengembangan kebijakan dan proses kepegawaian melalui kontrol lingkungan kerja [5]. Kepuasan kerja dikatakan sebagai nilai penting dalam perusahaan karena dalam peningkatan kepuasan kerja pegawai maka akan meningkatkan kinerja dan produktivitas perusahaan [6]. Kemudian pegawai yang memiliki komitmen organisasional yang tinggi akan bersedia memberikan kontribusi yang lebih besar dari pada yang diharapkan dalam rangka mewujudkan tujuan perusahaan [7].

Pada penelitian terdahulu menunjukkan hasil dimana pegawai tetap memiliki tingkat pemberdayaan, kepuasan kerja dan komitmen organisasional yang lebih tinggi daripada pegawai outsourcing [8]. Penelitian ini akan membahas lebih lanjut apabila penelitian dengan variabel yang sama diterapkan pada PT. Angkasa Pura I (Persero) Bandar Udara Juanda Surabaya untuk menganalisis bagaimana perbandingan pemberdayaan, kepuasan kerja dan komitmen organisasional antara pegawai tetap dan pegawai outsourcing.

\section{URAIAN PENELITIAN}

\section{A. Outsourcing}

Outsourcing adalah hubungan kontrak antara penyediaan layanan bisnis oleh penyedia layanan eksternal [9]. Dengan kata lain perusahaan membuat sebuah persetujuan dengan perusahaan lain untuk melakukan beberapa pekerjaan. Penelitian terdahulu mengatakan outsourcing adalah kegiatan memindahkan beberapa aktivitas di perusahaan kepada pihak lain, termasuk dalam hal pengambilan keputusan yang telah diatur dengan perjanjian kontrak [10]. Outsourcing juga dikatakan sebagai aktivitas dimana supplier atau pihak 
pemasok menyediakan layanan kepada pihak perusahaan berdasarkan perjanjian yang telah disepakati [11].

\section{B. Pegawai Tetap}

Pegawai tetap adalah pegawai yang menerima atau memperoleh imbalan dalam jumlah tertentu secara teratur atau berkala [12]. Pegawai tetap merupakan pegawai swasta, pegawai negeri dan penerima pensiun. Imbalan pegawai tetap bisa berupa gaji, beragam tunjangan, penghasilan tidak teratu seperti bonus, honorarium jasa produksi, gratifikasi dan lain sebagainya. Berdasarkan Peraturan Dirjen Pajak nomor 31/PJ/2009, pegawai tetap merupakan pegawai yang menerima penghasilan secara teratur dalam jumlah tertentu, termasuk anggota dewan komisaris dan anggota dewan pengawas yang secara teratur terus menerus ikut mengelola kegiatan perusahaan secara langsung, serta pegawai yang bekerja berdasarkan kontrak untuk suatu jangka waktu tertentu sepanjang pegawai yang bersangkutan bekerja penuh (full time) dalam pekerjaan tersebut.

\section{Pemberdayaan}

Pemberdayaan adalah sebuah proses untuk memperkuat perasaan individu terhadap efektivitas mereka di antara anggota organisasi lainnya [13]. Mengingat pesatnya kemajuan sains dan teknologi seiring dengan meningkatnya persaingan global, pemberdayaan dirasa penting untuk meningkatkan keefektifan sebuah perusahaan [14]. Pemberdayaan didefinisikan dalam beberapa perspektif yang berbeda yaitu pendekatan proses, pendekatan struktural dan pendekatan psikologis [15]. Pemberdayaan telah dianggap sebagai konsep penting karena berpotensi mempengaruhi hasil yang menguntungkan individu dan organisasi.

\section{Kepuasan Kerja}

Kepuasan kerja didefinisikan sebagai reaksi afektif terhadap pekerjaan yang dihasilkan dari perbandingan hasil yang dirasakan dengan yang diinginkan. Kepuasan kerja diartikan sejauh mana individu menyukai atau tidak menyukai pekerjaan mereka [16]. Individu yang memiliki tingkat kepuasan kerja yang tinggi umumnya memiliki sikap positif terhadap pekerjaan mereka. Sebaliknya, jika mereka memiliki tingkat kepuasan kerja yang rendah, mereka umumnya memiliki sikap negatif terhadap pekerjaan mereka [17]. Kepuasan kerja pegawai juga dipengaruhi oleh budaya organisasi perusahaan [18].

\section{E. Komitmen Organisasional}

Komitmen organisasional merupakan ikatan individu dengan organisasi. Pegawai yang memiliki komitmen tinggi terhadap pekerjaanya menunjukkan keinginan yang lebih tinggi untuk terlibat dalam kegiatan organisasional yang baik untuk mempertahankan status pekerjaan mereka . Mereka cenderung lebih puas dengan situasi pekerjaan mereka daripada pegawai lainnya. Komitmen Organisasional juga mempengaruhi peningkatan modal intelektual dan kinerja keuangan perusahaan [19][20].
Tabel 1 .

Instrumen Pernyataan Kuesioner

\begin{tabular}{|c|c|c|}
\hline Variabel & Indikator & Sumber \\
\hline $\begin{array}{l}\text { Pemberdayaan } \\
\text { (P) }\end{array}$ & $\begin{array}{l}\text { P1. Pekerjaan yang dilakukan memiliki } \\
\text { makna pribadi untuk pegawai } \\
\text { P2. Pegawai memiliki rasa percaya diri } \\
\text { terhadap kemampuan mereka dalam } \\
\text { melakukan pekerjaan dan selalu yakin dapat } \\
\text { mencapai pekerjaan yang telah ditargetkan } \\
\text { P3. Pegawai memiliki hak dalam menentukan } \\
\text { bagaimana cara mereka melakukan pekerjaan } \\
\text { P4. Pegawai sangat menyukai segala sesuatu } \\
\text { yang terjadi di dalam departemennya }\end{array}$ & [8] \\
\hline $\begin{array}{l}\text { Kepuasan } \\
\text { Kerja (KK) }\end{array}$ & $\begin{array}{l}\text { KK1. Pegawai merasa gaji yang diterima } \\
\text { setara dengan beban pekerjaan yang } \\
\text { dilakukan } \\
\text { KK2. Hanya ada sedikit kesempatan promosi } \\
\text { jabatan dalam pekerjaan pegawai } \\
\text { KK3. Cara atasan pegawai cukup kompeten } \\
\text { dalam menangani para pegawainya } \\
\text { KK4. Pegawai merasa puas dengan tunjangan } \\
\text { yang diterima } \\
\text { KK5. Pegawai mendapatkan penghargaan / } \\
\text { pengakuan ketika melakukan pekerjaan } \\
\text { dengan baik } \\
\text { KK6. Dengan adanya peraturan dan prosedur } \\
\text { operasional, membuat pegawai melakukan } \\
\text { pekerjaan dengan baik } \\
\text { KK7. Pegawai dapat bekerjasama dengan } \\
\text { baik dengan rekan kerjanya } \\
\text { KK8. Pegawai merasa pekerjaan yang } \\
\text { dikerjakan tidak berarti/tidak dihargai } \\
\text { KK9. Pegawai merasa komunikasi yang } \\
\text { terjalin antara seluruh anggota organisasi di } \\
\text { dalam perusahaan sudah baik }\end{array}$ & [21] \\
\hline $\begin{array}{l}\text { Komitmen } \\
\text { Organisasional } \\
(\mathrm{KO})\end{array}$ & $\begin{array}{l}\text { KO1. Pegawai merasa senang jika } \\
\text { menghabiskan sisa karir di perusahaan } \\
\text { tempat bekerja dan memiliki ikatan secara } \\
\text { emosional dengan perusahaan tempatnya } \\
\text { bekerja } \\
\text { KO2. Pegawai memegang teguh visi dan } \\
\text { misi dalam melaksanakan pekerjaan sehari- } \\
\text { hari dan merasa masalah yang dihadapi } \\
\text { perusahaan juga merupakan masalahnya } \\
\text { KO3. Pegawai tidak rela kehilangan } \\
\text { hubungan persahabatan dengan rekan kerja } \\
\text { apabila keluar dari perusahaan tempatnya } \\
\text { bekerja saat ini dan enggan mencari } \\
\text { pekerjaan di perusahaan lain karena sudah } \\
\text { nyaman dengan perusahaan tempat bekerja } \\
\text { saat ini }\end{array}$ & [8] \\
\hline
\end{tabular}

\section{METODE PENELITIAN}

Penelitian ini menguji 3 hipotesis sesuai dengan penelitian terdahulu yaitu penelitian dari Han, et al,. [8] dan Jordan et al [21] hipotesis-hipotesis yang digunakan dalam penelitian ini, yaitu :

1. Terdapat perbedaan pemberdayaan antara pegawai tetap dengan pegawai outsourcing.

2. Terdapat perbedaan kepuasan kerja antara pegawai tetap dengan pegawai outsourcing.

3. Terdapat perbedaan komitmen organisasional antara pegawai tetap dengan pegawai outsourcing.

Pengumpulan data dalam penelitian ini dilakukan dengan metode survei menggunakan kuesioner yang disebarkan secara offline. Penyebaran kuesioner dilakukan di PT. Angkasa Pura I (Persero) Bandar Udara Juanda Surabaya dengan purposive sampling method. Kuesioner terdiri dari 3 bagian. Pertama 
data karakteristik responden (usia, jenis kelamin, pendidikan terakhir, status pernikahan, status kepegawaian, departemen, lama bekerja, pendapatan, tempat tinggal, dan kendaraan). Kedua berupa persetujuan dari instrumen pernyataan yang ditunjukkan pada Tabel 1, serta yang ketiga berisikan kolom kritik dan saran. Kuesioner menggunakan skala likert 5 (lima) poin, yaitu poin 1 (satu) sangat tidak setuju hingga poin 5 (lima) sangat setuju. Pengumpulan data dilaksanakan pada Mei 2017 dan terkumpul 127 responden yang kemudian dilakukan analisis data.

\section{HASIL DAN DISKUSI}

\section{A. Analisis Karakteristik Responden}

Responden penelitian mayoritas berada di rentang usia 2530 tahun $(33,9 \%)$ dengan status pernikahan sebanyak $(61,4 \%)$ sudah menikah dan sebanyak $(38,6 \%)$ belum menikah. Jenis kelamin responden penelitian menunjukkan sebanyak $(54,3 \%)$ responden laki-laki dan $(45,7 \%)$ responden perempuan. Status kepegawaian responden berjumlah sama yaitu $(50 \%)$ pegawai tetap dan (50\%) pegawai outsourcing. Responden penelitian paling banyak berada pada departemen Shared Service sebanyak $(26,8 \%)$. Lama bekerja responden di dominasi oleh responden yang bekerja 0-5 tahun dengan mayoritas pendapatannya berada di rentang $\mathrm{Rp} 4.000 .000$ - Rp 6.000.000 sebanyak (53,5\%). Tempat tinggal responden di dominasi oleh responden yang tinggal di rumah pribadi sebanyak $(44,1 \%)$ dan kendaraan yang digunakan responden untuk berangkat bekerja di dominasi oleh sepeda motor yaitu sebanyak $(75,6 \%)$

\section{B. Confirmatory Factor Analysis}

Confirmatory factor analysis dalam penelitian ini dijadikan metode untuk menguji validitas dan reliabilitas. Confirmatory factor dan reliability analysis digunakan untuk mengkonfirmasi seluruh indikator-indikator yang terdapat dalam penelitian apakah pernyataan yang ada dalam kuesioner terkait dengan pemberdayaan, kepuasan kerja, dan komitmen organisasional sudah memenuhi kriteria valid dan reliabel.. Variabel dan indikator mampu mendukung penelitian apabila nilai standardized regression weight $\geq 0,60$ agar dapat dinyatakan valid. Reliabilitas menunjukkan konsistensi suatu alat ukur di dalam mengukur gejala yang sama. Item pengukuran dikatakan reliabel ketika nilai composite reliability memenuhi $\geq 0,60$. Hasil uji validitas dan reliabitas, 3 variabel meliputi pemberdayaan, kepuasan kerja, dan komitmen organisasional menunjukkan hasil yang baik dengan keseluruhan nilai loading factor yang berada diatas nilai minumum atau nilai standar.

Berdasarkan hasil uji validitas dan reliabitas yang ditunjukkan Tabel 2., 3 variabel meliputi pemberdayaan, kepuasan kerja, dan komitmen organisasional menunjukkan hasil yang baik dengan keseluruhan nilai loading factor yang berada diatas nilai minumum atau nilai standar. Namun pada indikator KK9 memiliki nilai loading factor dibawah nilai minimum, maka dari itu indikator KK9 akan dihapuskan dan tidak diikut sertakan pada analisis selanjutnya.

\section{Independent Sample T-test}

Uji-t pada penelitian ini melibatkan dua kelompok sampel pada penelitian yaitu pegawai tetap dan pegawai outsourcing.
Uji-t ini dilakukan untuk mengetahui perbandingan paling signifikan dari jawaban-jawaban yang diberikan oleh kedua kelompok sampel tersebut terhadap variabel-variabel penelitian.

Tabel 2.

Uji Validitas dan Realibilitas

\begin{tabular}{llccc}
\hline Variabel & Indikator & $\begin{array}{c}\text { Loading } \\
\text { Factor } \\
\geq \mathbf{0 , 6 0}\end{array}$ & $\begin{array}{c}\text { Cronbach } \\
\text { Alpha } \\
\mathbf{0 0 , 6 0}\end{array}$ & Keterangan \\
\hline Pemberdayaan & P1 & 0,79 & 0,84 & Valid \\
& P2 & 0,67 & & Valid \\
& P3 & 0,78 & & Valid \\
& P4 & 0,79 & & \\
\hline & & & & \\
\hline \multirow{2}{*}{ Valid }
\end{tabular}

Uji-t dilakukan dengan melihat hasil dari Levene's Test for Equality Variance kemudian dilanjutkan dengan meninjau hasil signifikansi dari uji-t.

Tabel 3.

Levene's dan t-test Pemberdayaan

\begin{tabular}{|c|c|c|c|c|c|}
\hline \multirow{2}{*}{\multicolumn{2}{|c|}{ Variabel }} & \multicolumn{2}{|c|}{ Levene's Test } & \multicolumn{2}{|c|}{ t-test } \\
\hline & & $\mathbf{F}$ & Sig. & $t$ & Sig. \\
\hline \multirow[b]{2}{*}{ Pemberdayaan } & $\begin{array}{l}\text { Equal } \\
\text { variances } \\
\text { assumed }\end{array}$ & & & 2,097 & 0,038 \\
\hline & $\begin{array}{l}\text { Equal } \\
\text { variances } \\
\text { not assumed }\end{array}$ & 4,662 & 0,033 & 2,097 & 0,038 \\
\hline
\end{tabular}

Hasil dari Levene's Test varibel pemberdayaan yang dilihat dari niliai F-hitung untuk asumsi varians adalah 4,622 dengan angka (Sig.) $0,033<0,05$, yang berarti varians populasi dari kedua kelompok memiliki perbedaan. Kemudian hasil dari thitung variabel pemberdayaan adalah 2,097 dengan angka (Sig.) 0,038. Berdasarkan hasil angka (Sig.) 0,038< 0,05 maka HO ditolak. Artinya terdapat perbedaan pemberdayaan antara pegawai tetap dengan pegawai outsourcing.

Tabel 4.

Levene's dan t-test Kepuasan Kerja

\begin{tabular}{|c|c|c|c|c|c|}
\hline \multirow{2}{*}{\multicolumn{2}{|c|}{ Variabel }} & \multicolumn{2}{|c|}{ Levene's Test } & \multicolumn{2}{|c|}{ t-test } \\
\hline & & $\mathbf{F}$ & Sig. & $t$ & Sig. \\
\hline \multirow{2}{*}{$\begin{array}{c}\text { Kepuasan } \\
\text { Kerja }\end{array}$} & $\begin{array}{l}\text { Equal } \\
\text { variances } \\
\text { assumed }\end{array}$ & \multirow{2}{*}{1,122} & \multirow{2}{*}{0,292} & 3,390 & 0,001 \\
\hline & $\begin{array}{l}\text { Equal } \\
\text { variances } \\
\text { not assumed }\end{array}$ & & & 3,390 & 0,001 \\
\hline
\end{tabular}

Berdasarkan hasil dari Levene's Test pada Tabel 4. variabel kepuasan kerja yang dilihat dari niliai F-hitung untuk asumsi varians adalah 1,122 dengan angka (Sig.) 0,292 > 0,05, yang berarti varians populasi dari kedua kelompok memiliki 
persamaan atau homogen. Kemudian hasil dari t-hitung variabel kepuasan kerja adalah 3,390 dengan angka (Sig.) 0,001. Berdasarkan hasil angka (Sig.) 0,001 $<0,05$ maka $\mathrm{H}_{0}$ ditolak. Artinya terdapat perbedaan kepuasan kerja antara pegawai tetap dengan pegawai outsourcing.

Berdasarkan hasil dari Levene's Test pada Tabel 5. variabel komitmen organisasional yang dilihat dari niliai F-hitung untuk asumsi varians adalah 0,118 dengan angka (Sig.) 0,731 $>0,05$, yang berarti varians populasi dari kedua kelompok memiliki persamaan atau homogen. Kemudian hasil dari thitung variabel komitmen organisasional adalah 4,567 dengan angka (Sig.) 0,000. Berdasarkan hasil angka (Sig.) 0,000 < 0,05 maka $\mathrm{H}_{0}$ ditolak. Artinya terdapat perbedaan komitmen organisasional antara pegawai tetap dengan pegawai outsourcing.

Tabel 5.

\begin{tabular}{|c|c|c|c|c|c|}
\hline \multirow{2}{*}{\multicolumn{2}{|c|}{ Variabel }} & \multicolumn{2}{|c|}{ Levene's Test } & \multicolumn{2}{|c|}{ t-test } \\
\hline & & $\mathbf{F}$ & Sig. & $t$ & Sig. \\
\hline \multirow{2}{*}{$\begin{array}{c}\text { Komitmen } \\
\text { Organisasional }\end{array}$} & $\begin{array}{l}\text { Equal } \\
\text { variances } \\
\text { assumed }\end{array}$ & \multirow{2}{*}{0,118} & \multirow{2}{*}{0,731} & 4,567 & 0,000 \\
\hline & $\begin{array}{l}\text { Equal } \\
\text { variances } \\
\text { not assumed }\end{array}$ & & & 4,567 & 0,000 \\
\hline
\end{tabular}

\section{A. Implikasi Manajerial}

Implikasi manajerial bertujuan sebagai rekomendasi manajerial yang dapat diterapkan oleh perusahaan pengguna maupun penyedia layanan jasa outsourcing. Pada sub bab ini akan dijabarkan mengenai hal-hal yang dapat dijadikan referensi bagi perusahaan objek penelitian dalam menjalankan bisnisnya berdasarkan hasil dan analisis penelitian. Berdasarkan hasil analisis statistik deskriptif sebagian besar pegawai memiliki masa kerja berkisar 0-5 tahun. Hal ini menunjukkan bahwa pegawai di perusahaan terbilang cukup baru. Dilihat dari rentang usia, mayoritas pegawai berusia 2530 tahun. Dapat dikatakan bahwa pegawai dengan rentang usia tersebut masih senang mencari tempat kerja baru dengan harapan mendapatkan pekerjaan yang lebih baik. Maka dari itu kemungkinan untuk pegawai keluar dari perusahaan tinggi. Sehingga perusahaan harus mempersiapkan strategi dalam hal pengembangan karir untuk para pegawainya agar pegawai memiliki komitmen yang tinggi untuk tetap bekerja di perusahaan.

Jika dilihat dari hasil analisis t-test, menunjukkan bahwa dari tiga variabel yakni pemberdayaan, kepuasan kerja, dan komitmen organisasional, pegawai tetap memiliki nilai yang lebih tinggi dari pegawai outsourcing. Hal ini dapat mengindikasikan menurunnya kinerja dari perusahaan karena adanya kesenjangan antara pegawai tetap dan pegawai outsourcingnya. Kurangnya pemberdayaan, kepuasan kerja, dan komitmen organisasional pada pegawai outsourcing tentunya akan memberikan dampak buruk juga kepada perusahaan pengguna layanan outsourcing. Maka dari itu, diharapkan perusahaan penyedia layanan outsourcing untuk lebih memberikan motivasi, tunjangan yang sesuai, dan strategi lainnya agar pemberdayaan, kepuasan kerja, dan komitmen organisasional dari pegawai outsourcing meningkat. Sehingga, ketika pegawai outsourcing bekerja pada perusahaan penerima layanan outsourcing, mereka melakukan pekerjaan dengan senang hati tanpa ada perasaan dikesampingkan oleh perusahaan.

\section{KESIMPULAN DAN SARAN}

A. Kesimpulan

Berdasarkan analisis yang telah dilakukan pada bab sebelumnya, didapatkan beberapa hasil dari penelitian ini, yakni sebagai berikut.

1. Hipotesis 1 diterima. Adanya perbedaan antara pegawai tetap dan pegawai outsourcing yang diuji dari pemberdayaan. Dimana pegawai tetap memiliki nilai ratarata yang lebih tinggi dibandingkan pegawai outsourcing.

2. Hipotesis 2 diterima. Adanya perbedaan antara pegawai tetap dan pegawai outsourcing yang diuji dari kepuasan kerja. Dimana pegawai tetap memiliki nilai rata-rata yang lebih tinggi dibandingkan pegawai outsourcing.

3. Hipotesis 3 diterima. Adanya perbedaan antara pegawai tetap dan pegawai outsourcng yang diuji dari komitmen organisasional. Dimana pegawai tetap memiliki nilai ratarata yang lebih tinggi dibandingkan pegawai outsourcing.

4. Terdapat perbedaan varians antara kelompok pegawai tetap dan pegawai outsourcing pada variabel pemberdayaan. Sedangkan pada variabel kepuasan kerja dan komitmen organisasional tidak terdapat perbedaan varians atau persepsi pada kedua kelompok tersebut.

\section{B. Saran}

Berdasarkan penelitian yang telah dilakukan, berikut merupakan saran yang ditujukan baik untuk penelitian selanjutnya dan untuk objek amatan. Dari hasil penelitian ini, dapat disarankan agar perusahaan baik dari penyedia layanan outsourcing maupun penerima layanan outsourcing untuk meningkatkan indikator-indikator yang tidak dominan, sehingga perusahaan dapat menjalankan kegiatan operasionalnya dengan lebih baik lagi. Untuk penelitian selanjutnya diharapkan dapat menambahkan variabel dan indikator untuk lebih mengetahui lebih dalam perbandingan persepsi antara pegawai tetap dan pegawai outsourcing.

\section{DAFTAR PUSTAKA}

[1] B. Leavy, "Outsourcing strategies: opportunities and risks," Strateg. Leadersh., vol. 32, no. 6, pp. 20-25, Dec. 2004.

[2] W. King, "The IS Organization of the Future: Impacts of Global Sourcing," Inf. Syst. Manag., vol. 24, no. 2, pp. 121-128, 2007.

[3] K. H. Lau and J. Zhang, "Drivers and Obstacles of Outsourcing Practices in China," Int. J. Phys. Distrib. Logist. Manag., vol. 36, no. 10, pp. 776$792,2006$.

[4] I. G. N. Universitas Udayana. Fakultas Ekonomi, D. K. Sintaasih, and I. G. Riana, Efek Pemoderasian Status Kepegawaian Pada Pengaruh Motivasi dan Komitmen Organisaisonal Terhadap Kinerja Karyawan. 2016.

[5] Chang and C. Liu, "Employee empowerment, innovative behavior and job productivity of public health nurses: A cross-sectional questionnaire survey," Int. J. Nurs. Stud., vol. 45, no. 10, pp. 1442-1448, 2008.

[6] G. Güleryüz, S. Güney, E. M. AydIn, and Ö. Aşan, "The mediating effect of job satisfaction between emotional intelligence and organisational commitment of nurses: A questionnaire survey," Int. J. Nurs. Stud., vol. 45, no. 11, pp. 1625-1635, 2008.

[7] S. Agus and W. Erni, "Pengaruh kepemimpian dan komitmen organisasional terhadap kinerja karyawan dengan budaya kolektivitas variabel moderasi," J. Manaj. Sumber Daya Mns., vol. 6, no. 1, pp. 1-10, 2012.

[8] S. S. Han, S. J. Moon, and K. E. Yun, "Empowerment, job satisfaction, 
and organizational commitment: comparison of permanent and temporary nurses in Korea," Appl. Nurs. Res., vol. 22, pp. 15-20, 2009.

[9] M. Belcourt, "Outsourcing — The benefits and the risks."

[10]P. R. Krugman and O. Maurice, Ekonomi Internasional: Teori dan kebijakan, edisi kedua, alih bahasa oleh Haris Munandar dan Faisal Basri. Jakarta: Raja Grafindo Persada, 1999.

[11]T. Elfing and J. Perry, "Outsourcing technical service: stages of development," Long Range Plann., vol. 27, no. 5, pp. 42-51, 1994.

[12] Faisal, How to be A Smarter Taxpayer: Bagaimana menjadi Wajib Pajak. Jakarta: Grasindo, 2009.

[13] J. A. Conger, R. N. Kanungo, and S. T. Menon, "Charismatic leadership and follower effects," J. Organ. Behav., vol. 21, no. 7, pp. 747-767, 2000.

[14]A. Ergeneli, G. S. Ari, and S. Metin, "Psychological empowerment and its relationship to trust in immediate managers," J. Bus. Res., vol. 60, pp. 41-49, 2007.

[15]K. W. Thomas and B. A. Velthouse, "Cognitive elements of empowerment: An 'interpretive' model of intrinsic task motivation," Acad. Manag. Rev., vol. 15, no. 4, pp. 666-681, 1990.
[16]J. Ivancevich and M. Matteson, Organizational Behaviour and Management, 6th ed. New York: Mc Graw Hill, 2002.

[17] S. P. Robbins, Organizational Behavior, Tenth Edition, 10th ed. Jakarta: PT Macanan Jaya Cemerlang, 2003.

[18] N. Fatimah, N. Wessiani, and Y. Rahmawati, "Analisis Faktor-faktor keberhasilan penerapan budaya kaizen pada perusahaan manufaktur," $J$. Sains dan Seni ITS, vol. 6, no. 1, pp. 47-49, 2017.

[19] K. R. P. Dewi, N. P. Negoro, and Y. Rahmawati, "Conceptual framework of intellectual capital influence to corporate efficiency," IPTEK J. Proceding Ser., vol. 1, no. 1, p. 48, 2016.

[20] K. R. P. Dewi, N. P. Negoro, and Y. Rahmawati, "Peran Human Capital terhadap efisiensi Perusahaan Perbankan di Indonesia," J. Sains dan Seni ITS, vol. 6, no. 1, pp. 18-23, 2017.

[21]G. Jordan, G. Miglič, I. Todorović, and M. Marič, "Psychological Empowerment, Job Satisfaction and Organizational Commitment Among Lecturers in Higher Education: Comparison of Six CEE Countries," Organizacija, vol. 50, no. 1, Jan. 2017. 